\title{
Intranasal Ethmoidectomy
}

National Cancer Institute

\section{Source}

National Cancer Institute. Intranasal Ethmoidectomy. NCI Thesaurus. Code C51898.

Surgical removal of part of the ethmoid bone, using an intra-nasl approach. 